\title{
Impact of a Local Nigerian Rice Variety and Wheat on the Tolerance of Geographical Strains of Sitophilus oryzae to Dichlorvos
}

\author{
Olajire Ayodele Gbaye ${ }^{1}$, Emmanuel Ayobami Oyeniyi ${ }^{1, ~ *, ~ M u y i d e e n ~ F o l o r u n s h o ~}{ }^{1}$, \\ Graham Holloway $^{2}$ \\ ${ }^{1}$ Biology Department, Federal University of Technology, Akure, Nigeria \\ ${ }^{2}$ Centre for Wildlife Assessment and Conservation, School of Biological Sciences, University of Reading, Berkshire, UK
}

Email address:

eaoyeniyi@futa.edu.ng (E. A. Oyeniyi), oyemmayo@gmail.com (E. A. Oyeniyi)

${ }^{*}$ Corresponding author

\section{To cite this article:}

Olajire Ayodele Gbaye, Emmanuel Ayobami Oyeniyi, Muyideen Folorunsho, Graham Holloway. Impact of a Local Nigerian Rice Variety and Wheat on the Tolerance of Geographical Strains of Sitophilus oryzae to Dichlorvos. American Journal of Entomology.

Vol. 3, No. 2, 2019, pp. 30-35. doi: 10.11648/j.aje.20190302.11

Received: March 30, 2019; Accepted: May 5, 2019; Published: June 10, 2019

\begin{abstract}
Rice weevil, Sitophilus oryzae, a cosmopolitan pest of stored cereals (including wheat and rice) is moved around inadvertently through global cereal trade. In this study, we consider the effect of strain origin and host food on the tolerance of $S$. oryzae to dichlorvos, a common insecticide used to protect stored grains in Nigeria. Three geographical strains of $S$. oryzae (Nigeria, Trinidad and Morocco) were bred separately on Ofada rice (a Nigerian local rice variety) and wheat and then exposed to dichlorvos. The data were analyzed using analysis of variance and General Linear Model, probit analysis was used to estimate $\mathrm{LC}_{50}$ and $\mathrm{LC}_{95}$ values. The strain by food combinations varied significantly in their tolerance to dichlorvos. Overall, the Nigerian strain was the least tolerant. Nonetheless, for all strains novel host food influenced their tolerance positively; wheat in the case of the Nigerian strain and Ofada rice for the exotic strains. The results were discussed in terms of varying body size among the strains and physiological effect when insects find themselves in novel environments. The risk posed to local Nigerian rice varieties is considered through the import of exotic strains of $S$. oryzae, especially when entering the country on wheat.
\end{abstract}

Keywords: DDVP, Ofada Rice, Exotic Strain, Insecticide Tolerance, Cereal Import, Novel Environment, Pest Management

\section{Introduction}

Rice (Oryzae sativa L.) and wheat (Triticum spp. L.) grains are essential food commodities for the majority of the populace in many developing countries. They have contributed to the diet, economy and strategic food security planning policies of government of many nations in subSahara Africa. For instance, between December 2015 and May 2018, the Nigerian government has been able to save about 5.49 billion US dollars by reducing rice importation by $95 \%$ [1]. This has been facilitated by an upscale in local rice production. In spite of the considerable progress recorded in rice production, the country still struggles to achieve selfsufficiency in many other cereal crops, especially wheat. The domestic wheat production is estimated to be about 250,000 tons in year 2016 while over 4 million tons is needed to satisfy national demand [2].

Aside from the desire to achieve self-sufficiency in rice production, many local rice varieties are returning to favour. Ofada rice is one of such local variety. Ofada rice is an unpolished Nigerian rice variety which has a distinctive aroma and flavour. It is served wrapped in leaves of Thaumatococcus daniellii (miracle berry) and accompanied by a spicy stew of hot pepper, tomatoes and chopped meats. Because of the current demand, a budding market has emerged for this rice variety. As well as the local demand, it is also packaged and exported to Nigerians living outside the country helping to create employment. However, Ofada rice is highly susceptible to the common rice pest, Sitophilus 
oryzae L. [3] which threatens production

The rice weevil, $S$. oryzae is a cosmopolitan pest of stored cereals. It has been estimated to account for cereal grain loss between $20-30 \%$ and $5-10 \%$ in tropical and temperate regions, respectively $[4,5]$. The immature stages develop within the grain. Both the larval and adult stage of $S$. oryzae devours the kernel, resulting in quality deterioration, weight loss and reduction of market value. The global trade in cereal grain has been associated with widespread movement of $S$. oryzae around the world [6]. In Nigeria, rice imports are declining but the large deficit in national wheat demand necessitates importation of this commodity to cover the shortfall in demand. Consequently, it is expected that exotic strains of $S$. oryzae could be introduced into the country. It is well known that different geographical strains of $S$. oryzae possess different attributes and vary in their destructive ability [7].

To protect stored rice from pest infestation, farmers and post-harvest handlers in Nigeria rely heavily on the use of chemicals [8]. The organophosphate Dichlorvos (dichlorovinyl dimethyl phosphate- DDVP) is one of the commonest insecticides available for use in Nigeria [8-11]. Due to the low level of literacy among farmers and merchants handling pesticides in Nigeria, application at a rate higher than the manufacturer's specification is inevitable. This has led to the development of pest resistance and high pesticide residue in diverse stored products [7]. This resulted in a ban on cereal exports from Nigeria into the European Union due to unacceptably high levels of DDVP in 2015 [11].

In spite of studies on the development of $S$. oryzae on local rice varieties and its response to synthetic chemicals $[3,7$, 12]; the impact of indigenous Nigerian rice varieties on insecticide tolerance in $S$. oryzae remains unexplored. Information on the insecticide response of strains of $S$. oryzae from Nigeria and exotic strains from other countries will help in its management on stored rice. This study investigates the response of Nigerian and foreign strains of $S$. oryzae reared on Ofada rice and wheat to DDVP.

\section{Material and Methods}

\subsection{Cereal Procurement and Insect Rearing}

The cereal grains used in this study were Ofada rice (a variety native to the southwest of Nigeria) and Wheat (Hard Red Winter Variety). The cereals were purchased from Oba market in Akure and were disinfested by placing them in the freezer for one week at $-18^{\circ} \mathrm{C}$. They were thereafter left for three days on the laboratory bench to warm up to ambient temperature before use.

Three strains of Sitophilus oryzae were assayed in this study. The stock cultures were obtained as follows: "Nigeria strain" was obtained from naturally infested Ofada rice obtained from Oba market in Akure, Ondo State, Nigeria; two exotic strains, Trinidad and Morocco, were obtained from the Centre for Wildlife Assessment and Conservation, School of Biological Sciences, University of Reading, Reading, UK where they have been cultured on wheat for over 100 generations without exposure to insecticides. The three strains were reared to $F_{2}$ generations separately on Ofada rice and wheat grains to eliminate maternally inherited dietary effects [13]. The insects were reared inside $0.5 \mathrm{~L}$ plastic containers covered with muslin cloth and kept inside insect rearing cages in the Biology Laboratory of Federal University of Technology, Akure, Nigeria at $28 \pm 2{ }^{\circ} \mathrm{C}$ and 70 $75 \%$ relative humidity.

\subsection{Preparation of Insecticides}

The commercial grade insecticide, 2, 2-Dichlorovinyl dimethyl phosphate, DDVP, (Delvap ${ }^{\circledR} 1000 \mathrm{EC}$ ) used for the study was procured from an agrochemical store in Akure. Laboratory grade acetone (99\%, BDH Chemicals Ltd, Poole, England) was used as diluent for the insecticide. Six different concentrations of DDVP were prepared $(0.00001 \%$, $0.0001 \%, 0.0005 \%, 0.001 \%, 0.005 \%$ and $0.01 \%$ ) and acetone only $(0.0 \%)$ served as the control. To prevent evaporation of acetone, each concentration was prepared and retained in an air-tight reagent bottle $(5 \mathrm{mls})$.

\subsection{Characteristics and Morphometrics of Cereal Grains}

The moisture content of the cereals was analyzed using MB35 Halogen moisture analyzer (OHAUUS/USA). The lengths and widths of twenty randomly selected undamaged grains from each cereal type were measured using a micrometer screw gauge (model - RQHS NORM 2002/95/EC). The other seed characteristics (colour and shape) were subjectively determined visually using a x10 magnification hand lens.

\subsection{Morphometrics of S. Oryzae}

Adult $S$. oryzae that emerged from the different cereals were sexed following Halstead [14]. The criteria for sexing are the shape and structure of the rostrum, and the form of the tip of the abdomen. Fifteen male and fifteen female adult weevils were randomly selected from each culture (strain $\mathrm{x}$ food) and their lengths (abdomen to the rostrum tip) were measured with a stage micrometer under a stereomicroscope.

\subsection{Tolerance Bioassay}

Impregnated filter paper technique, FAO method 15 [15], was used for the bioassay and for each strain by food combination each treatment was replicated four times. Filter papers (Whatman No 1: $11 \mathrm{~cm}$ diameter) were doused with $0.5 \mathrm{ml}$ of a specific concentration of DDVP using a $1 \mathrm{ml}$ syringe. The treated papers were allowed to air dry and then placed on ceramic tiles $\left(15 \mathrm{~cm}^{2}\right)$. Twenty-five 3-5 days old unsexed adult $S$. oryzae were placed onto each treated filter paper. Each foilter paper was covered with a disposable plastic Petri dish ( $9 \mathrm{~cm}$ in diameter) lightly coated with Fluon (Poly tetrafluoro ethylene, PTFE, ACS109 Blades Biologicals Ltd, Kent, UK) to prevent weevils from climbing away from the treated filter paper. Mortality was assessed 6 hours after treatment based on previous studies by Gbaye et al. [11]. Weevils were considered dead when they did not 
move after their abdomens were pricked with a needle.

\subsection{Statistical Analysis}

The data were analysed using analysis of variance (ANOVA) and mean values were compared using Tukey's Test at $P<0.05$. Mortality data were subjected to probit analysis with $\log$ transformation of the concentration to determine the DDVP concentration lethal to $50 \%$ and $95 \%$ $\left(\mathrm{LC}_{50}\right.$ and $\left.\mathrm{LC}_{95}\right)$ of each strain of $S$. oryzae from each food [16]. General Linear Model (GLM) was used to investigate the main and interactive effects of strain, food type and concentration on the response of $S$. oryzae to DDVP. All analyses were carried out using Statistical Package for Social Sciences (SPSS) 22.0 software.

\section{Results}

\subsection{Characteristics and Morphometrics of Cereal Grains}

Table 1 show the characteristics and morphometrics of the cereals used for the study. Ofada rice grains were significantly longer $(P<0.05)$ and narrower than the wheat grains. The moisture content of wheat grains was however higher than those of Ofada rice.

\subsection{Morphometrics of S. Oryzae Strains}

The morphometrics of $S$. oryzae strains that emerged from each cereal are shown in Table 2. Generally, females were longer than males but the size difference is not always significant. Insects emerging from Ofada rice were shorter than their counterparts emerging from wheat grains $(P<$ 0.05). The Nigerian strain of $S$. oryzae was consistently shorter than the other two strains $(P<0.05)$. No significant difference $(P>0.05)$ existed between the body lengths of the strains from Morocco and Trinidad reared on both wheat and Ofada rice. However, wheat reared female weevils of the Morocco strain were significantly longer $(P<0.05)$ than males reared on Ofada rice.

Table 1. Morphometrics and seed characteristics of Ofada rice and Hard Red Winter wheat (Mean $\pm S . E, n=20$ in each case).

\begin{tabular}{lllll}
\hline \multirow{2}{*}{ Food type } & \multicolumn{2}{l}{ Grain morphometrics } & Grain characteristics \\
\cline { 2 - 5 } & Length $(\mathbf{m m})$ & Width $(\mathbf{m m})$ & \% Moisture & Colour \\
\hline Wheat & $5.88 \pm 0.11^{\mathrm{a}}$ & $3.55 \pm 0.04^{\mathrm{b}}$ & $11.50 \pm 0.24^{\mathrm{b}}$ & Reddish brown \\
Ofada rice & $6.20 \pm 0.20^{\mathrm{b}}$ & $2.78 \pm 0.04^{\mathrm{a}}$ & $9.52 \pm 0.35^{\mathrm{a}}$ & Dull white \\
\hline
\end{tabular}

Means within the same column followed by a different superscript letter are significantly different $(\mathrm{P}<0.05)$ from each other according to Tukey’s test.

Table 2. Body Length (mm) of S. oryzae strains reared on Ofada rice and Hard Red Winter wheat (Mean $\pm S E, n=15$ in each case).

\begin{tabular}{lll}
\hline Strains-by-food & Male & Female \\
\hline Nigeria on Wheat & $3.26 \pm 0.01^{\mathrm{a}}$ & $3.51 \pm 0.01^{\mathrm{a}}$ \\
Nigeria on Ofada rice & $3.09 \pm 0.02^{\mathrm{a}}$ & $3.39 \pm 0.01^{\mathrm{a}}$ \\
Trinidad on Wheat & $3.87 \pm 0.01^{\mathrm{b}}$ & $4.23 \pm 0.02^{\mathrm{d}}$ \\
Trinidad on Ofada rice & $3.79 \pm 0.01_{\mathrm{b}}$ & $4.06 \pm 0.02^{\mathrm{b}}$ \\
Morocco on Wheat & $3.87 \pm 0.02^{\mathrm{b}}$ & $4.14 \pm 0.01^{\mathrm{c}}$ \\
Morocco on Ofada rice & $3.71 \pm 0.01^{\mathrm{b}}$ & $3.97 \pm 0.02^{\mathrm{b}}$ \\
\hline
\end{tabular}

Means within the same column followed by a different superscript letter are significantly different $(\mathrm{P}<0.05)$ from each other according to Tukey's test.

\subsection{Response of Nigerian and Exotic Strains of S. Oryzae to DDVP Treatment}

The responses of three strains (Nigeria, Morocco and Trinidad) of $S$. oryzae reared on wheat and Ofada rice to different concentrations of DDVP are shown in Figure 1. Regardless of the experimental concentration, Nigeria strain of $S$. oryzae reared on wheat showed higher tolerance to DDVP than their counterpart reared on Ofada rice (Figure 1A). By contrast, Morocco strain of $S$. oryzae reared on Ofada rice showed higher tolerance to DDVP than their counterpart reared on wheat except at $0.00001 \%$ (Figure 1C). Trinidad strain however showed inconsistent effect of food on its response to different concentrations of DDVP (Figure 1B). There were significant effects $(P<0.001)$ of food (Nigeria: $F=182.93$, df $=1,36$; Trinidad: $F=18.58, \mathrm{df}=1$, 36; Morocco: $F=217.29$, df $=1,36$ ) and concentration (Nigeria: $F=372.01$, df $=5,36$; Trinidad: $F=271.46$, df $=5$,
36; Morocco: $F=825.31$, $\mathrm{df}=5,36$ ) on the response of each strain to DDVP. The interaction between food and concentration on each strain's response to DDVP was also significant (Nigeria: $F=4.95$, df $=5,36, P=0.002$; Trinidad: $F=6.66$, df $=5,36, P<0.001$; Morocco: $F=$ 33.94, df $=5,36, P<0.001)$.
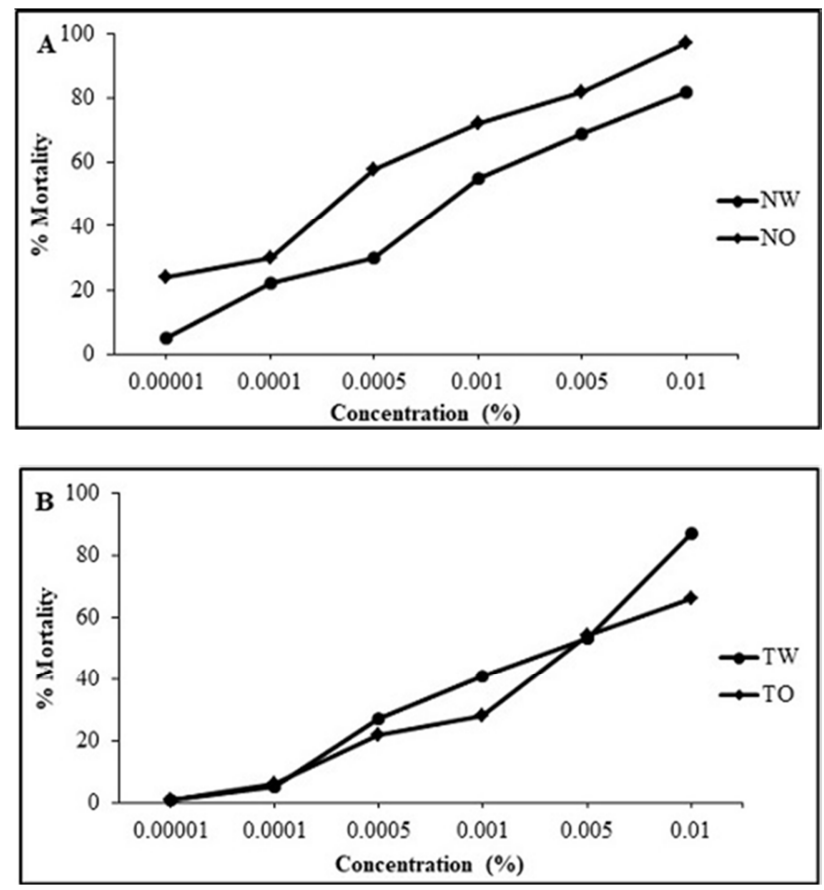


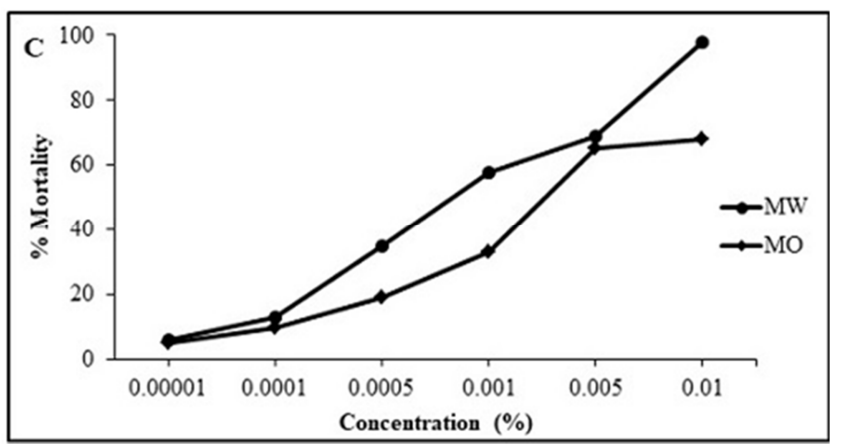

Figure 1. Effect of Ofada rice and wheat on the tolerance of $(A)$ Nigeria, $(B)$ Trinidad and (C) Morocco strains of S. oryzae to DDVP after 6 hours posttreatment.

NW: Nigeria strain on wheat; NO: Nigeria strain on Ofada rice; TW: Trinidad strain on wheat; TO: Trinidad strain on Ofada rice; MW: Morocco strain on wheat; MO: Morocco strain on Ofada rice

\subsection{GLM Analysis of Main and Interactive Effects of Strain, Food Host and Insecticide Concentration on S. Oryzae Response to DDVP}

GLM analysis showed significant effects $(P<0.001)$ of strain $(\mathrm{S})(F=270.89 ; \mathrm{df}=2,108)$ and concentration $(\mathrm{C})(F$ $=1205.81 ; \mathrm{df}=5,108)$ on the tolerance of $S$. oryzae to DDVP. However, the impact of food (F) alone was not significant $(F=1.44 ; \mathrm{df}=1,108 P=0.233)$. All the two-way interactions of the main factors had statistically significant effects $(P<0.001)$ on the response of the weevils to DDVP $(\mathrm{S} \times \mathrm{C}: F=5.83, \mathrm{df}=10,108 ; \mathrm{S} \times \mathrm{F}: F=166.74, \mathrm{df}=2,108$; $\mathrm{F} \times \mathrm{C}: F=17.24, \mathrm{df}=5,108)$. Likewise, there was significant effect of the three-way interaction of the factors on the tolerance of S. oryzae to DDVP $(\mathrm{S} \times \mathrm{F} \times \mathrm{C}: F=7.80, \mathrm{df}=10$, 108; $P<0.001)$.

\subsection{Lethal Concentrations [ $L C_{50}$ and $L C_{95}$ ] for $S$. Oryzae Reared on Ofada Rice and Wheat}

Figure 2 shows the lethal concentration of DDVP required to kill $50 \%$ and $95 \%$ of the different strains of $S$. oryzae reared on wheat and Ofada rice. The highest $\mathrm{LC}_{50}$ and $\mathrm{LC}_{95}$ of DDVP were required by Trinidad $(0.004 \mathrm{mg} / \mathrm{ml})$ and Morocco $(0.265 \mathrm{mg} / \mathrm{ml})$ strains, respectively, reared on Ofada rice. Higher concentrations of DDVP were required to achieve both $50 \%$ and $95 \%$ mortality in Trinidad and Morocco strains of $S$. oryzae reared on Ofada rice when compared to their counterpart reared on wheat grains. In contrast, the Nigeria strain reared on wheat grains required higher concentration of DDVP to achieve $50 \%$ and $90 \%$ mortality than their counterpart reared on Ofada rice. $\mathrm{LC}_{95}$ values revealed that Trinidad strain reared on Ofada rice was 7.3 times more tolerant of DDVP than their Nigeria counterpart reared on the same food; while Morocco strain reared on Ofada rice is 9.1 times more tolerant than the Nigeria strain on Ofada rice. On the contrary, Trinidad and Morocco strains reared on wheat were less tolerant of DDVP than their wheat-reared counterpart population from Nigeria.
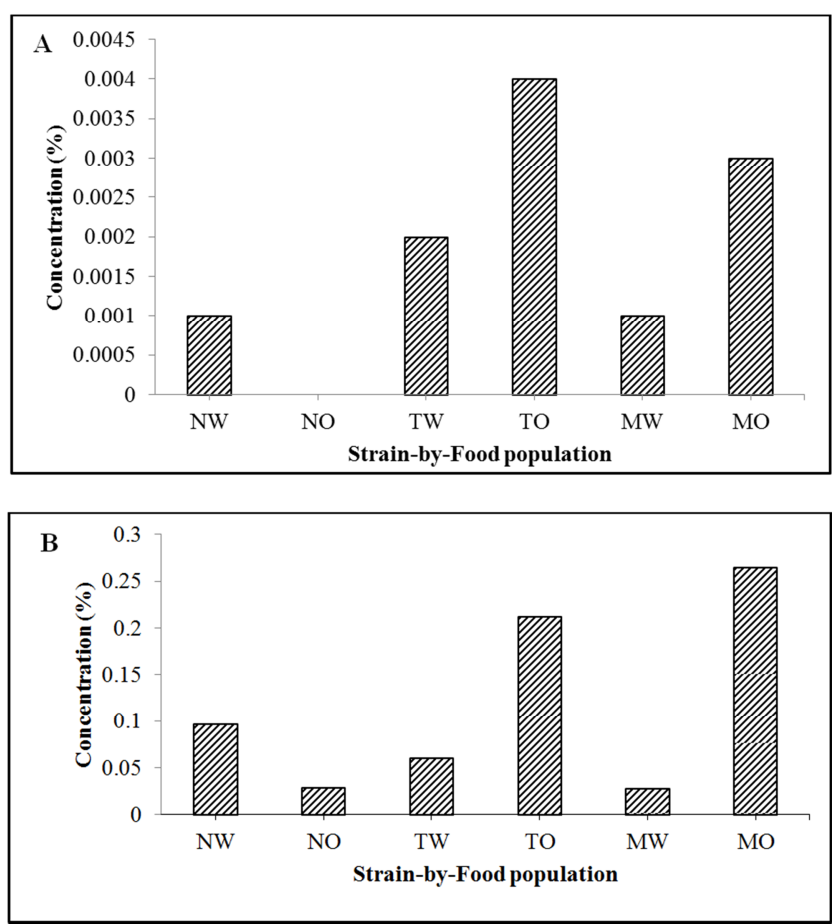

Figure 2. Lethal Concentration of DDVP required to cause (A) $50 \%$ and $(B)$ 95\% mortality in strains of S. oryzae after 6 hours of exposure.

NW: Nigeria strain on wheat; NO: Nigeria strain on Ofada rice; TW: Trindad strain on wheat; TO: Trinidad strain on Ofada rice; MW: Morocco strain on wheat; MO: Morocco strain on Ofada rice

Note: No value was displayed for $\mathrm{NO}$ in Figure $2 \mathrm{~A}$ because the $\mathrm{LC}_{50}$ is lesser than $0.0005 \%$.

\section{Discussion}

The results obtained from this study show that insecticide tolerance of $S$. oryzae to DDVP was significantly influenced by geographical origin and food type. Regardless of the geographical origin of $S$. oryzae, weevils emerging from Ofada rice were smaller than weevils emerging from wheat. This does not necessarily mean that wheat is a better host than Ofada rice since Gbaye and Ajiye [3] found that $S$. oryzae developed faster on Ofada rice. Fitness is determined by a combination of life history traits [17]; overall it is possible that weevils emerging from Ofada rice might be fitter than those emerging from wheat. The body size of wheat-reared weevil could have been influenced by the significantly higher moisture content observed in wheat grains than Ofada rice, as grain moisture content is known to affect life history characters in S. oryzae [18].

Additionally, the nutritional composition of the food type might have influenced the morphology of the emerging insects and this could have led to the observed differences in the body length of the same weevil strain reared on different food type [19]. The protein content of wheat is higher than that of rice [20] and this might influence growth rate. Quality of food has been noted as a key factor in the development of insect pests [21, 22]. Similarly, the shift in the food type (between "Ofada" and wheat) might have affected the biology of both the local and foreign $S$. oryzae strains due to 
delayed adult emergence observed for both first and second generation as a result of shifting between food host. This is in agreement with observation by Derera et al. [23] that a more favorable host food enhanced the rate of oviposition and development of an insect from egg to adult stage than a less favorable host.

Lethal concentration $\left(\mathrm{LC}_{50}\right)$ values revealed that Trinidad and Morocco $S$. oryzae strains that emerged from Ofada rice had elevated tolerance to DDVP compared with insects that emerged from wheat and also compared with the Nigeria strain. The primary food host of the Nigeria and foreign strains of $S$. oryzae used in this study were Ofada rice and wheat, respectively. The higher insecticide tolerances were associated with insects that had been reared on novel foodstuff. Insects breeding on novel food display higher levels of genetic variation than conspecifics in ancestral foodstuff [24]. Higher genetic variation could be associated with an ability of adult insects to tolerate toxin [25 - 28].

One of the factors that affect the response of an organism to insecticide is its geographical origin [29, 30]. Foreign weevils reared on novel food were larger in size and exhibited higher tolerance to DDVP than their Nigeria counterpart. The size of an insect can increase energy reserves; hence more energy would be available to tackle the insecticide [31, 32]. This might explain the higher tolerance of the bigger foreign strains.

The effects of strain and its interaction with concentration and food type were significant on the response of $S$. oryzae to DDVP. This indicates that the degree to which concentration of DDVP influenced the response of each weevil strain was greatly affected by the host food on which the insect strains were reared. A change in any of the factors considered in this study could therefore affect the susceptibility or tolerance of $S$. oryzae to DDVP as the interactions among the three factors [strain, concentration and food type] have significant impact on weevil vulnerability [33].

\section{Conclusion}

This study showed that if exotic strains of S. oryzae [especially on a different cereal grain] infest a local rice variety such as Ofada in Nigeria, they might become difficult to control with insecticides. Foreign strains of $S$. oryzae reared on novel food (Ofada) were thus observed to have exhibited higher level of tolerance to DDVP than their Nigeria counterparts. Similarly, morphological variations such as varying body size and physiological effect were observed to have existed among the strains of $S$. oryzae when they find themselves in novel environments. It is therefore vital to monitor the entrance and spread of exotic strains of $S$. oryzae into Nigeria which might cause future pest control failure. The largest sea port in Nigeria and the main point of entry of imported foods including wheat is Lagos, situated in the South West; this is also the principle region where Ofada rice is cultivated. Hence, effective monitoring for importation of $S$. oryzae will help to forestall potential losses in the expanding market of local Nigeria rice varieties such as
Ofada rice.

\section{References}

[1] Ogbe, A. (2018). Federal Government (FG) saves $\$ 5.49 \mathrm{~b}$ from rice importation. Accessed 25 June, 2018 from $\mathrm{https}$ ://economicconfidential.com/business/fg-saves-5-49bfrom-rice-importation/.

[2] Assefa, S., El Mourid, M., Onyango, P. O., Kpakpo, A., Ketata, H., Chebi, A. (2017). Unlocking the potential of wheat in sub-Sahara Africa. Wheat for Africa Updates Newsletter. 4: 1-4. http://sard-sc-wheat.icarda.org.

[3] Gbaye, O. A., Ajiye, O. B. (2016). Susceptibility level of some Nigerian hybrid and local rice varieties to Sitophilus oryzae L. (Coleoptera: Curculionidae). Int. J. Entomol. Res. 1: $10-13$.

[4] Dubey, N. K., Srivastava, B., Kumar. A. (2008). "Current status of plant products as botanical insecticides in storage pest management". J. Biopesticides 1 (2): 182-186.

[5] Rajashekar, Y., Shivanandappa, T. (2010). "A novel natural insecticide molecule for grain protection," in Stored Products Protection, Carvalho M O, Fields P G, Adler C S. et al., Eds., Proceedings of the 10th International Working Conference on Stored Product Protection. Julius-Kühn-Archiv 425: 913 - 917.

[6] Calpe, C. (2006). Rice International Commodity Profile. Food and Agriculture Organization of the United Nations, Markets and Trade Division, pp 1-23. Accessed 7 December, 2018 from http://www.fao.org/es/esc/en/15/70/highlight_533.html.

[7] Odeyemi, O. O., Ashamo, M. O., Akinkurolere, R. O., Olatunji, A. A. (2010). Resistance of strains of rice weevil, Sitophilus oryzae (Coleoptera: Curculionidae) to pirimiphos methyl. Proceedings of the 10th International Working Conference on Stored Product Protection. Julius-Kühn-Archiv 425: 167-172.

[8] Chedi, B. A. Z., Aliyu, M. (2010). Effect and management of acute dichlorvos poisoning in wistar rats. Bayero Pure Appl. Sci. J. 3 (2): 1-3.

[9] Lotti, M. (2001). Clinical toxicology of anticholinesterase agents in humans. In: Krieger R, (ed). Handbook of pesticide toxicology. Vol. 2. Agents. 2nd ed. Academic Press; San Diego, pp. 1043-1085.

[10] Booth, E. D., Jones, E., Elliott, B. M. (2007). Review of the in vitro and in vivo genotoxicity of Dichlorvos. Regul. Toxicol. Pharm. 49: 316. DOI: 10.1016/j.yrtph.2007.08.011.

[11] Gbaye, O. A., Ajiye, O. B. (2016). Susceptibility level of some Nigerian hybrid and local rice varieties to Sitophilus oryzae L. (Coleoptera: Curculionidae). Int. J. Entomol. Res. 1: 10-13.

[12] Ashamo, M. O. (2006). Relative susceptibility of some local and elite rice varieties to the rice weevil, Sitophilus oryzae L. (Coleoptera: Curculionidae). J. Food Agric. Environ. 4 (1): 249-252.

[13] Gbaye, O. A., Holloway, G. J. (2011). Varietal effects of cowpea, Vigna unguiculata, on tolerance to malathion in Callosobruchus maculatus (Coleoptera: Bruchidae). J. Stored Prod. Res. 47: 365-371. 
[14] Halstead, D. G. H. (1963). External Sex different in storedproducts coleopteran. Bull. Entomol. Res. 54: 119- 134.

[15] Anonymous (1974). Recommended methods for the detection and measurement of resistance of agricultural pests to pesticides. Tentative method for adults of some major beetle pests of stored cereals with malathion and lindane. FAO method No 15. FAO Plant Prot. Bull. 22: 127-137.

[16] Finney, D. J. (1971). "Probit Analysis". Cambridge University Press, Cambridge, London, 333pp.

[17] Povey, S. R., Holloway, G. J. (1992). The effect of energy tradeoffs on life history and fitness in the rice weevil, Sitophilus oryzae. Oikos 64: 441-450.

[18] Holloway, G. J. (1985). The effect of increased grain moisture content on some life history characters of Sitophilus oryzae (L.) after staining egg plugs with acid fuchsin. J. Stored Prod. Res. 21: 165-169.

[19] Oyeniyi, E. A., Gbaye, O. A., Holloway, G. J. (2015). Interactive effect of cowpea variety, dose and exposure time on bruchid tolerance to botanical pesticides. African Crop Sci. J. 23 (2): 165-175.

[20] TTI (The Times of India. (2017). Rice vs Wheat: Which is better? Accessed 7 December, 2018 from https://timesofindia.indiatimes.com/rice-vs-wheat-which-isbetter/articleshow/58339012.cms.

[21] Athanassiou, C. G., Kavallieratos, N. G., Chintzoglou, G. J. (2008). Effectiveness of spinosad dust against different populations of the confused flour beetle, Tribolium confusum Jacquelin du val. J. Stored Prod. Res. 44: 47-51.

[22] Williams, S. B., Murdock, L. L., Kharel, K., Baributsa, D. (2016). Grain size and grain depth restrict oxygen movement in leaky hermetic containers and contribute to protective effect. J. Stored Prod. Res. 69: 65-71.

[23] Derera, J., Pixley, K. V., Giga, P. D. (1999). Inheritance of maize weevil resistance in maize hybrids among lines in South Africa, Mexico and CIMMIT-Zimbabwe. In: Maize Production technology for the future: Challenges and opportunities. Proceedings of the South Eastern and Southern African Regiona maize conference, 21-25 September 1998. Addis Ababa, Ethopia: EARO (Ethiopia Agricultural Research Organization) and CIMMYT, Addisa Ababa. Pp. 19-23.
[24] Holloway, G. J., Povey, S. R., Sibly, R. M. (1990). The effect of new environment on adapted genetic architecture. Heredity 64: 323-330.

[25] Smith, R. H. (1990). Adaptation of Callosobruchus species to competition. In: Fujii, K., Gatehouse, A. M. R., Johnson, C. D., Mitchell, R., Yoshida, Y. (Eds.), Bruchids and Legumes: Economics, Ecology and Coevolution. Kluwer, Dordrecht, Netherland. Pp. 351-360.

[26] Daniel, S. H., Smith, R. H. (1994). Functional anatomy of the egg pore in Callosobruchus maculatus: a trade-off between gas exchange and protective functions? Physiol. Entomol. 19: $30-38$

[27] Guedes, R. N. C., Smith, R. H., Guedes, N. M. P. (2003). Host suitability, respiration rate and the outcome of larval competition in strains of the cowpea weevil, Callosobruchus maculatus. Physiol. Entomol. 28: 298-305.

[28] Vamosi, S. M. (2005). Interactive effects of larval host and competition on adult fitness: an experimental test with seed beetle (Coleoptera: Bruchidae). Funct. Ecol. 19: 859-864.

[29] Kljajic, P., Peric, I. (2007). Effectiveness of wheat-applied contact insecticide against Sitophilus granarius (L.) originating from different populations. J. Stored Prod. Res. 43: 523-529.

[30] Gbaye, O. A., Millard, J. C., Holloway, G. J. (2012). Synergistic effects of geographical strain, temperature and larval food on insecticide tolerance in Callosobruchus maculatus (F.) J. Appl. Entomol. 136: 282-291.

[31] Holloway, G. J. (1986). A theoretical examination of the classical theory of inheritance of insecticide resistance and the genetics of time to knockdown and dry body weight in Sitophilus oryzae (L.) (Coleoptera: Curculionidae). Bull. Entomol. Res. 76: 661-670.

[32] Guedes, R. N. C., Oliveira, E. E., Guedes, N. M. P., Ribeiro, B., Serrao, J. E. (2006). Cost and mitigation of insecticide resistance in the maize weevil, Sitophilus zeamais. Physiol. Entomol. 31: 289-305.

[33] Gbaye, O. A., Holloway, G. J. (2011). Varietal effects of cowpea, Vigna unguiculata, on tolerance to malathion in Callosobruchus maculatus (Coleoptera: Bruchidae). J. Stored Prod. Res. 47: 365-371. 